\title{
LA FUNDAMENTACIÓN DE LA DECLARACIÓN DE HECHOS PROBADOS EN EL NUEVO PROCESO PENAL. UN DIAGNÓSTICO*
}

\author{
Daniela Accatino Scagliotti**
}

\begin{abstract}
RESUMEN
El estudio ofrece un diagnóstico de la aplicación práctica que ha recibido la nueva regulación de la exigencia de fundamentación de las conclusiones probatorias en las sentencias penales. La autora da cuenta de la existencia de una serie de vacilaciones en el camino hacia una motivación exhaustiva, que resulte acorde al "modelo analítico" que fijan las directrices del Código Procesal Penal y explora luego qué factores pueden explicar la persistencia de esas incertidumbres. Especial importancia se atribuye a algunas carencias y equivocos conceptuales presentes en nuestra cultura procesal. Se destaca sobre todo el negativo impacto que tiene el predominio -reforzado por la introducción del estándar de prueba "más allá de toda duda razonable" - de una noción subjetivista de prueba, que vincula conceptualmente la prueba con la creencia o la convicción del tribunal.
\end{abstract}

PRUEBA - FUNDAMENTACIÓN DE LA SENTENCIA PENAL - PROCESO PENAL

\section{The statement of reasons for findings of fact in the new Chilean criminal procedure. A diagnosis}

\begin{abstract}
The study offers an analysis of the observance of the new regulations requiring the statement of reasons for the conclusions on evidence in criminal judicial decisions. The author discusses the existence of several doubts on the road towards a solid statement of reasons that proves to be harmonious with the "analytical model" set down in the directives of the Code of Criminal Procedure. She then explores which factors can explain the persistence of these uncertainties. Special importance is attributed to some conceptual deficiencies and errors present in the Chilean procedural culture. Of note, above all, is the adverse impact that the predominance -reinforced by the introduction of the standard of proof "beyond all reasonable doubt"- of a subjectivist notion of evidence bas.
\end{abstract}

\section{EVIDENCE - STATEMENT OF REASONS FOR JUDICIAL DECISIONS - CRIMINAL PROCEDURE}

\footnotetext{
* Este trabajo ha sido realizado en el marco del proyecto DID-UACH No S-200431 "La fundamentación de los hechos en la sentencia penal", del que la autora es investigadora principal.

** Abogada, Doctora en Derecho, Profesora de Teoría del Derecho en la Facultad de Ciencias Jurídicas y Sociales de la Universidad Austral de Chile, Casilla 567, Valdivia, Chile. Correo electrónico: daccatino@uach.cl. Artículo recibido el 30 de septiembre de 2006 y aceptado para su publicación por el Comité Editorial el 6 de noviembre de 2006.
} 


\section{INTRODUCCIÓN}

$\mathrm{L}$ os problemas de la justificación jurídica monopolizaron por largo tiempo la atención prestada a la exigencia de fundamentación de las decisiones judiciales. un tiempo a esta parte, sin embargo, la justificación de la quaestio facti ha ganado nueva visibilidad como garantía del derecho a la prueba y condición de legitimidad del poder judicial. ${ }^{1}$ Desde la primera perspectiva se destaca cómo el derecho de las partes a presentar pruebas en un proceso público y contradictorio se vuelve ilusorio si es que no comprende la exigibilidad de una respuesta justificada del juez, en la que se dé cuenta que las pruebas aportadas han sido tomadas en consideración y valoradas racionalmente. El segundo punto de vista pone de relieve, en cambio, la amplitud de los espacios abiertos al ejercicio discrecional del poder del juez en el ámbito de la valoración de la prueba, de modo que la justificación pública de sus conclusiones parece el único camino para exorcizar el riesgo de arbitrariedad.

El nuevo Código Procesal Penal chileno (en adelante, CPP) se inscribe claramente en esa reciente tendencia, en cuanto intensifica las exigencias de justificación de la declaración de los hechos que se tienen por probados en la sentencia definitiva. Este trabajo intenta un diagnóstico de la acogida que esa innovación ha encontrado en nuestra práctica procesal. ${ }^{2}$ Dos son las hipótesis que en él se exploran. La primera sugiere que, a pesar del esfuerzo legislativo por fortalecer el rol y precisar el contenido de la exigencia de fundamentación de los hechos en las sentencias penales, no existe, en nuestra práctica procesal penal, claridad sobre las condiciones que la justificación ofrecida por un tribunal de juicio oral debe satisfacer para ser juzgada suficiente, ni sobre el alcance del control que pueden ejercer los tribunales superiores de justicia sobre los fundamentos de las conclusiones probatorias a través del recurso de nulidad. La segunda hipótesis vincula esas incertidumbres y vacilaciones en el camino hacia un modelo más exigente de fundamentación de las conclusiones probatorias con algunas carencias y equívocos conceptuales presentes en nuestra cultura jurídica. En particular se destaca el efecto adverso que se sigue del arraigo de la noción subjetivista de prueba, que vincula conceptualmente la prueba con la convicción del tribunal.

${ }^{1}$ Vid., por ejemplo, Lo, H. L., "The judicial duty to give reasons”, en Legal Studies, Vol. 20, No 1 , 2000 , pp. 42-65 y Ferrer Beltrán, J., "Derecho a la prueba y racionalidad de las decisiones judiciales”, en Jueces para la democracia, 47, 2003, pp. 27-34.

${ }^{2}$ La investigación jurisprudencial en la que este diagnóstico se funda se encuentra recogida fundamentalmente en tres tesis para optar al grado de Licenciado en Ciencias Jurídicas de la Universidad Austral de Chile, que fueron dirigidas por la autora: Villanueva, I., La fundamentación de los hechos en las sentencias penales. Una comparación entre el antiguo y el nuevo proceso penal, 2005; Villarroel, P., La justificación de la "duda razonable" en las nuevas sentencias penales, 2005; Coñuecar, V., El control de la fundamentación de las conclusiones probatorias a través del recurso de nulidad, 2006. Desgraciadamente varias de las sentencias consultadas no se encuentran publicadas ni están disponibles en bases de datos electrónicas. Por esa razón, cuando se haga referencia en este trabajo a ciertos rasgos de nuestra práctica judicial sólo se indicarán al lector, a título meramente ejemplar, algunas sentencias publicadas o disponibles electrónicamente. 
Para avanzar hacia la justificación de esas hipótesis, comenzaré por caracterizar brevemente la situación de la fundamentación de los hechos durante la vigencia del antiguo Código de Procedimiento Penal (1.); luego revisaré las claves del nuevo régimen que la exigencia de motivación fáctica encuentra en el CPP (2.), así como las incertidumbres a que ha dado lugar su aplicación (3.); para concluir con un análisis de los factores que podrían explicar la tenacidad de esas dificultades interpretativas, considerando sobre todo su conexión con el predominio, más o menos consciente, entre nuestros juristas y jueces, de una noción subjetivista de prueba (4.).

\section{EL REINO DE LAS APARIENCIAS: LA FUNDAMENTACIÓN DE LOS HECHOS durante la vigencia del antiguo Código de Procedimiento Penal}

Nuestra República acogió tempranamente la tendencia europea a imponer a los jueces el deber de fundamentar sus decisiones. ${ }^{3}$ Así, el Código de Procedimiento Penal de 1906 la contemplaba tanto respecto de las sentencias definitivas de primera instancia, como de las sentencias de segunda instancia que revocaran o modificaran la de otro tribunal. En particular, con respecto a la motivación de los hechos, disponía que las sentencias debían contener "las consideraciones en cuya virtud se dan por probados o por no probados los hechos atribuidos a los procesados; o los que éstos alegan en su descargo, ya para negar su participación, ya para eximirse de responsabilidad, ya para atenuar ésta" (artículo 500 numeral $4^{\circ}$ ). Por otra parte el artículo 541 numeral $9^{\circ}$ preveía como causal de casación en la forma el no haber sido extendida la sentencia en la forma dispuesta por la ley.

Durante la vigencia del antiguo Código tendió a primar en la práctica de nuestros tribunales un patrón de fundamentación mínima o puramente aparente, caracterizado por: a) la inclusión de abultadas partes expositivas en las que se consignaban detalladamente cada una de las actuaciones procesales tendientes al esclarecimiento de los hechos; b) la enumeración de los medios de prueba estimados por el tribunal; c) la declaración de los hechos que se tienen por probados (o, en su caso, por no probados), unida a la afirmación de que el conjunto de medios probatorios que antes se ha enumerado, apreciados conforme a las reglas legales, es suficiente (o, en su caso, insuficiente) para tenerlos por acreditados. ${ }^{4}$

Se trata, como se puede apreciar, de un modelo que elude explicitar las razones justificativas del valor atribuido a cada medio de prueba así como de su suficiencia (o insuficiencia) para dar (o no dar) por acreditados los hechos constitutivos del caso y que omite, por regla general, cualquier referencia a la prueba desestimada. A pesar de que estas omisiones parecen infringir el tenor de la exigencia del artículo 500 numeral $4^{\circ}$ del

${ }^{3}$ Cfr, Hanisch, H., "Contribución al estudio del principio y de la práctica de fundamentación de las sentencias en Chile durante el siglo XIX”, en Revista de Estudios Histórico-Jurídicos, VII, 1982, pp. 131-173.

${ }^{4}$ Cfr. Baytelman, A., "La fundamentación de la sentencia en el nuevo proceso penal", en AAVV, Nuevo Proceso Penal, Editorial Conosur, Santiago, 2000 y Villanueva, I., op. cit., p. 25ss. 
Código de 1906, ellas no fueron, en general, cuestionadas por los tribunales superiores de justicia al conocer de los recursos de casación en la forma por carecer la sentencia de fundamentos. De hecho, el control ejercido con respecto a la fundamentación de los hechos a través de la casación en la forma tendió a configurarse, salvo contadas excepciones, como un control estrictamente formal de la presencia gráfica de consideraciones relativas a la prueba y de su consistencia interna. ${ }^{5}$ El único control referido a la valoración de la prueba que fue admitido se ejerció a través de la casación en el fondo por infracción de las leyes reguladoras de la prueba, cuando éstas asignaban un determinado valor a un cierto medio de prueba.

A pesar de que cabía perfectamente una interpretación estricta de la exigencia de fundamentación del artículo 500 numeral $4^{\circ}$, su devaluada interpretación dominante resultaba consistente con la vigencia respecto de varios medios de prueba de un sistema de prueba legal o tasada (de modo que, siendo en esos casos una regla legal la razón justificativa del valor probatorio atribuido, ella podría presumirse conocida) y con la desprotección del derecho de defensa y la escasa vigencia del principio contradictorio que es característica de un modelo procesal inquisitivo.

\section{HACIA LA FUNDAMENTACIÓN}

\section{DE LOS HECHOS EN SERIO: EL NUEVO MODELO LEGAL}

Las disposiciones del nuevo Código Procesal Penal relativas a la fundamentación de las resoluciones judiciales sugieren una visión crítica de la forma en que esa exigencia fue interpretada en el marco del antiguo proceso inquisitivo. Así, en primer lugar, el artículo 36 prevé, por primera vez en nuestro ordenamiento procesal, un principio general en virtud del cual toda resolución judicial debe ser fundada, con excepción tan sólo de aquellas que se pronuncien sobre cuestiones de mero trámite, y se encarga de precisar luego que "la simple relación de los documentos del procedimiento o la mención de los medios de prueba o solicitudes de los intervinientes no sustituirá en caso alguno la fundamentación". 6

El rechazo del patrón mínimo o aparente de fundamentación dominante bajo la vigencia del antiguo Código resulta igualmente claro en el caso de las disposiciones relativas

${ }^{5}$ Cfr. Villanueva, I., op. cit., pp. 27-28; con respecto a la misma tendencia en los procesos civiles y laborales vid. Romero, A., "Las consideraciones de hecho y de derecho de la sentencia: un derecho esencial del justiciable", en Revista Chilena de Derecho, Vol. 27, No 3, pp. 571-579.

${ }^{6}$ Una consecuencia del establecimiento de esta exigencia general de fundamentación que interesa mencionar, aunque no sea objeto directo de análisis en este trabajo, es que ella hace necesaria la expresión de razones también respecto de las sentencias dictadas por las Cortes de Apelaciones y por la Corte Suprema al conocer de algún recurso. La extendida práctica anterior a la Reforma del "Vistos, se confirma" -amparada en la antigua legislación procesal penal- debiera, por consiguiente, haber desaparecido. Una evaluación crítica de la efectividad de ese cambio puede verse en Benavides, H., Fundamentación en las Cortes de Apelaciones del nuevo proceso penal, tesis para optar al grado de Licenciado en Ciencias Jurídicas y Sociales de la Universidad Austral de Chile, dirigida por el profesor J. Quintana, Valdivia, 2005. 
a la justificación de las conclusiones probatorias en las sentencias definitivas (esto es, el artículo 342 literal e y el artículo 297, sobre la valoración de la prueba, al que el primero se remite). Ellas requieren: (a) que el tribunal se haga cargo en su fundamentación "de toda la prueba producida, incluso de aquella que hubiere desestimado, indicando en tal caso las razones que hubiere tenido en cuenta para hacerlo"; (b) que el tribunal señale el o los medios de prueba mediante los cuales da por acreditados cada uno de los hechos y circunstancias que dan por probados; (c) que esa fundamentación permita "la reproducción del razonamiento utilizado para alcanzar las conclusiones" a que se llegue en la sentencia y que no contradiga "los principios de la lógica, las máximas de la experiencia y los conocimientos científicamente afianzados" (las cursivas han sido añadidas). Por último, en el marco del nuevo sistema de recursos procesales la omisión de alguno de los requisitos de fundamentación exigidos se encuentra expresamente prevista como motivo absoluto de nulidad de la sentencia y del juicio oral por el artículo 374 literal e del CPP.

Las normas legales antes indicadas parecen dar acogida en nuestra legislación a la más avanzada interpretación doctrinal comparada de la exigencia de motivación de los enunciados probatorios, que defiende un modelo de justificación -que algunos autores denominan "analítico"- que requiere una exposición pormenorizada de todas las pruebas practicadas, del valor probatorio que se les ha asignado y las razones que lo sustentan y de la cadena de inferencias que permite tener por justificadas las conclusiones probatorias. ${ }^{7}$

La progresiva afirmación doctrinal de este modelo en el derecho comparado europeo constituye el fruto del abandono de la concepción emocional y puramente potestativa de la libre valoración de la prueba, largamente predominante hasta tiempos recientes, que concebía al juicio sobre la prueba como una especie de epifanía que sobreviene al juez en contacto inmediato con la evidencia y que no es susceptible de racionalización ni de control. ${ }^{8}$ Una vez que la regla de la libre valoración de la prueba deja de ser entendida

\footnotetext{
${ }^{7}$ Cfr., por ejemplo, Taruffo, M., "Motivazione della sentenza (diritto comparato e straniero)", en Enciclopedia Giuridica, Treccani, Roma, 1990; Andrés Ibáñez, P., “Acerca de la motivación de los hechos en la sentencia penal”, en Doxa, 12, 1992 y del mismo autor también: “'Carpintería' de la sentencia penal (en materia de 'hechos')", en Revista del Poder Judicial, 49, 1998 y "La argumentación probatoria y su expresión en la sentencia", en Estudios de Derecho Judicial, 32, 2000; Igartúa Salaverría, J., Valoración de la prueba, motivación y control en el proceso penal, Tirant Lo Blanch, Valencia, 1995, pp. 189ss. y del mismo autor también $L a$ motivación de las sentencias, imperativo constitucional, Centro de estudios Políticos y Constitucionales, Madrid, 2003, pp. 135ss.; Iacoviello, F. M., la motivazione Della sentenza penale e il suo controllo in cassazione, Giuffrè, Milán, 1997, pp. 115ss.; Colomer Hernández, I., La motivación de las sentencias: sus exigencias constitucionales y legales, Tirant lo Blanc, Valencia, 2003. La distinción entre un modelo "analítico" y un modelo "holista" de valoración de la prueba es utilizada por: Damaska, M., "Atomistic and holistic evaluation of evidence: A comparative view", en Clerck, D. S. (ed.), Comparative and Private International Law. Studies in honor of J. H. Merryman, Berlin, 1990; Twining, W., Rethinking Evidence. Exploratory Essays, Northestern U. Press, Evanston, 1994 (1 ${ }^{\mathrm{a}}$ ed. 1990), pp. 219ss.; Taruffo, M., La prova dei fatti giuridici, Giuffrè, Milàn, 1992, pp. 281ss. (existe traductión al castellano de J. Ferrer, La prueba de los hechos, Trotta, Madrid, 2002) y Gascón Abellán, M., Los hechos en el derecho. Bases argumentales de la prueba, Marcial Pons, Madrid, 1999, pp. 223 ss.

${ }^{8}$ Como se sabe, esta concepción se extendió en Europa continental a partir de la adopción, en el Code d' Instruction Criminelle de 1808, de la fórmula de la conviction intime. La instrucción que de acuerdo al artículo 342 de ese cuerpo legal debía leerse a los jurados franceses declaraba que "la ley no pide
} 
como criterio positivo de decisión que remite a la creencia subjetiva del juez y pasa a ser concebida como una regla negativa, que excluye la tasación legal de la prueba, pero que no libera al juez de la sujeción a estándares generales de racionalidad, la motivación de las conclusiones probatorias adquiere un papel protagónico como garantía y herramienta de control de su racionalidad. Y, desde esta perspectiva, el modelo analítico de motivación de los hechos representa la forma -exhaustiva y diferenciada- que la fundamentación debe asumir para poder cumplir adecuadamente esa función. Por otra parte ese modelo y, en particular, la exigencia que la motivación se estructure en forma dialógica y comprenda no sólo la justificación lineal de la hipótesis fáctica acogida, sino también la valoración singularizada de las pruebas desestimadas y la confrontación de las hipótesis desechadas, refleja adecuadamente el carácter relacional de la justificación de los enunciados que declaran hechos probados respecto del conjunto de elementos de juicio representado por todas las pruebas admitidas y practicadas en el proceso y constituye el necesario correlato de la garantía de un proceso contradictorio. ${ }^{9}$

A pesar de la insistencia doctrinal en las bondades del modelo analítico de motivación de las conclusiones probatorias, no se trata aún de un modelo generalizado en la práctica procesal penal comparada ${ }^{10}$. La situación en Chile debiera ser diferente, en cuanto es la

cuenta de los medios por los cuales se ha formado una convicción; (...) ella les exige que se interroguen a sí mismos en silencio y en recogimiento y que busquen determinar, en la sinceridad de su conciencia, qué impresión han causado en su razonamiento las pruebas aportadas contra el acusado y los medios de defensa. (...) (L)a ley les hace una sola pregunta, que compendia toda la medida de su deber: ¿tenéis una convicción íntima?” (citada por Walter, G., Libre apreciación de la prueba, Temis, Bogotá, 1985 (ed. Original 1979), p. 76). Aunque las reformas procesales que se emprendieron en otros sistemas jurídicos durante el siglo XIX rechazaron en principio el cariz irracionalista de la fórmula de la conviction intime y recurrieron a fórmulas más cautas o neutrales -como el "prudente apprezamento" de la legislación italiana o la "libre convicción” alemana (la fórmula española de la "apreciación según su conciencia” mantiene, en cambio, el tono subjetivista) - y aunque el jurado fue sustituido en muchos casos por jueces profesionales, también en estos ordenamientos tendió a predominar hasta bien avanzado el siglo XX una concepción subjetivista de la libre convicción. Así, por ejemplo, en España, todavía en 1980 el Tribunal Supremo sostenía que “(el) Tribunal puede formar libremente su convicción respecto a los problemas fácticos que defiera el proceso de que se trate, sin supeditarla a criterio racional de sana crítica, lógico o cualquier otro que no sea el de su recta e imparcial conciencia" (citado en Ferrer Beltrán, J., Prueba y verdad en el derecho, Marcial Pons, Madrid-Barcelona, 2002, p. 92). En Alemania, por otra parte, G. Walter constataba aún en 1979 el predominio tanto en la jurisprudencia como en la doctrina de un "modelo absolutamente subjetivista" que considera que la libre valoración de la prueba remite como criterio necesario y suficiente a la "aprobación subjetiva del juez" (op. cit., p. 152).

${ }^{9}$ Con respecto al carácter relacional de la justificación de los enunciados probatorios vid. Mendonca, D., Interpretación y aplicación del derecho, Servicio de Publicaciones de la Universidad de Almería, Almería, 1997, pp. 77-8 y Ferrer Beltrán, J., Prueba y verdad.., cit., p. 38. En relación a la necesaria conexión entre la estructura de la motivación y la configuración contradictoria del proceso, vid. Ferrajoli, L., Derecho y razón. Teoría del garantismo penal, trad. cast. De P. Andrés, A. Ruiz, J.C. Bayón y J. Terradillos, Trotta, Madrid, 1995 (ed. original 1989), pp. 150-2 y Iacoviello, F., op. cit., pp. 215 ss.

${ }^{10}$ Cfr. Andrés Ibáñez, P., “Acerca de la motivación de los hechos...”, cit.; Gascón Abellán, M., op. cit., pp. 223 ss.; Amodio, E., "Motivazione della sentenza penal”, en Enciclopedia del Diritto, Vol. XXVII, Giuffrè, Milán, 1977, p. 235; Taruffo, M., "La fisonomía della sentenza in Italia”, en AAVV, La sentenza in Europa. Metodo, tecnica e stile, CEDAM, Padua, 1988, pp. 201ss. 
propia ley la que especifica, en el mismo sentido sugerido por ese modelo doctrinal, las exigencias de contenido que debe satisfacer la justificación de la declaración de hechos probados. Un análisis de las prácticas de fundamentación de los Tribunales de Juicio Oral en lo Penal sugiere, sin embargo, otra cosa.

\section{LA RESISTENCIA DE LAS VIEJAS PRÁCticas: DifiCUltadeS EN LA APLICACIÓN DEL NUEVO MODELO LEGAL DE FUNDAMENTACIÓN}

Si bien no cabe afirmar que las sentencias dictadas por los Tribunales de Juicio Oral en lo Penal respondan a un patrón único de fundamentación, llama la atención que un número considerable de ellas omita tanto justificar la valoración individual de las pruebas, como enunciar la cadena de inferencias que permite aceptar como justificadas las conclusiones probatorias, y se limite a dar cuenta de una valoración conjunta y global de la prueba, a través de fórmulas del tipo “...la prueba rendida por el Ministerio Público, reseñada en el fundamento precedente, especialmente ... es suficiente, apreciada libremente, para tener por establecidos, más allá de toda duda razonable, los siguientes hechos ...". ${ }^{11}$ Este patrón de fundamentación no parece corresponder al modelo "analítico" antes aludido. Se aproxima más bien a una versión pobre del modelo "holista o globalizador" con el que el primero suele ser contrastado. Este último se caracteriza por la declaración como probados de ciertos hechos que se integran en una narración coherente, unida o bien a la afirmación de que ellos resultan de la valoración conjunta de los medios de prueba aportados al proceso, o bien a la incorporación al relato fáctico de referencias a los medios de prueba que dan sustento a la versión de los hechos que se tiene por probada. ${ }^{12}$

El patrón predominante de fundamentación sólo ha sido objeto de revisión crítica por parte de las Cortes de Apelaciones y la Corte Suprema a través del recurso de nulidad en la medida en que conlleve la falta de justificación de la desestimación de alguna prueba aportada al juicio oral. ${ }^{13}$ Esta exigencia -respecto de la cual se aprecia un elevado grado

${ }^{11}$ Cfr. Villanueva, I., op. cit., pp. 30 y 35 y también Centro de Documentación Defensoría Penal Pública, Análisis de los controles de detención y absoluciones producidos en la IV Región de Coquimbo 2001-2002, Santiago, 2005, p. 46. Pueden consultarse como ejemplos de este patrón de fundamentación las siguientes sentencias: Sentencia del Tribunal de Juicio Oral en lo Penal (en adelante, STJOP) de Arica de 01 de marzo de 2004, RUC 0300088441-2, RIT 81-2004; del mismo Tribunal la sentencia de 16 de octubre de 2004, RUC 0400064136-2, RIT 91-2004 ; STJOP de Calama de 5 de mayo de 2004, RUC 0310004304-0, RIT 06-2004; STJOP de Antofagasta de 20 de mayo de 2002, RIT 5-2002; STJOP de Copiapó de 16 de julio de 2004, RUC 0210001533-4, RIT 44-2004; STJOP de La Serena de 4 de junio de 2004, RIT 39-2004; STJOP de Valparaíso de 13 de mayo de 2004, RUC 0400002206-9, RIT 07-2004; STJOP de Curicó de 14 de mayo de 2004, RUC 0300117283-1, RIT 13-2004; STJOP de Talca de 3 de agosto de 2006, RUC 0500396742-7, RIT 24-2006; STJOP de Temuco de 9 de noviembre de 2004, RUC 0300145395, RIT 097-2004. Las sentencias citadas pueden consultarse en www.lexisnexis.cl.

12 Vid. las referencias consignadas supra en la parte final de la nota 8.

${ }^{13}$ Cfr. Villanueva, op. cit., pp. 31-33 y 36. Pueden consultarse, por ejemplo: Sentencia de la Corte de Apelaciones de Antofagasta de 10 de junio de 2004, Rol 61-2004 (disponible en www.defensoriapenal.cl), 
de uniformidad en la práctica de decisión de los recursos de nulidad interpuestos por la causal de falta de fundamentación- constituye un cambio significativo en relación a las prácticas de control de las motivaciones anteriores a la reforma.

Sin embargo, las nuevas directrices fijadas por el CPP no requieren sólo la valoración individual de toda la prueba rendida, sino que exigen también que la fundamentación permita "la reproducción del razonamiento utilizado para alcanzar las conclusiones". Lo que esta directiva requiere es que el lector de la sentencia pueda reconstruir el camino entre las premisas del razonamiento probatorio (los elementos probatorios obtenidos de la valoración individual de las pruebas) y las conclusiones probatorias. Es lo mismo que el modelo analítico de fundamentación requiere cuando exige que se consigne la cadena de inferencias que permiten tener por justificadas las conclusiones probatorias. $Y$ es precisamente eso -además de la valoración individual de toda la prueba rendida- lo que parece faltar en las motivaciones que se aproximan al modelo holista o globalizador. Este punto no ha sido, sin embargo, objeto de control por las Cortes de Apelaciones. ${ }^{14}$ Ni ellas ni la Corte Suprema, en los casos en que ha fallado recursos de nulidad en que concurría también el motivo de nulidad relativo a la falta de fundamentación de las conclusiones probatorias, han fijado hasta ahora, a través de sus sentencias, criterios claros y estables que precisen cuando el razonamiento probatorio puede ser considerado suficientemente "reproducible". ${ }^{15}$

Sentencia de la Corte de Apelaciones de Copiapó de 17 de diciembre de 2004, Rol 237-2004 (disponible en www.lexisnexis.cl); Sentencia de la Corte Suprema de 6 de abril de 2005, Rol 5440-04 (disponible en www.lexisnexis.cl); Sentencia de la Corte de Apelaciones de Santiago de 5 de mayo de 2006, Rol 517-2006 (disponible en www.lexisnexis.cl). Una excepción relevante la constituye la sentencia de la Corte Suprema del 6 de septiembre de 2005, Rol 3118-2005 (disponible en www.lexisnexis.cl), en la que se objeta en general el recurso a la valoración global de la prueba; esa sentencia realiza la siguiente consideración para sostener que la resolución impugnada vulnera la exigencia de fundamentación prevista por el artículo 342 letra c) del CPP: "la sentenciadora declara que las conclusiones que (...) se exponen resultan de valorar la prueba rendida y 'analizada precedentemente', de conformidad con lo dispuesto en el artículo 297, pero lo cierto es que (...) si bien las pruebas son expuestas una a una en forma más bien desordenada, no se advierte "análisis" alguno de ellas, y mucho menos una exposición de cómo se han ido deduciendo, de cada una de ellas o del conjunto de varias, las conclusiones que con tanta seguridad se afirman” (considerando séptimo).

${ }^{14}$ Hay incluso algunas sentencias - como la de la Corte de Apelaciones de Antofagasta de 29 de septiembre de 2004, Rol 135-2004 (disponible en www.lexisnexis.cl)- que legitiman explícitamente el recurso a una valoración global de la prueba. Así, por ejemplo, la sentencia citada señala en su considerando cuarto que "si bien [los sentenciadores] efectuaron un análisis global de la prueba, han cumplido cabalmente con la letra c) del artículo 342 del Código procesal penal, ya que el legislador no ha exigido que la valoración de ella se efectúe pormenorizadamente, sino que contenga el señalamiento de los medios de prueba por los cuales se dan por acreditados los hechos". Luego agrega, en línea con la orientación jurisprudencial a la que se hace referencia en la nota anterior, que "se han hecho cargo de la prueba desestimada, indicando las razones que tuvieron para efectuarlo".

${ }^{15}$ En mi opinión los tribunales superiores deberían proporcionar orientación a través de la auctoritas de sus razones, expresadas en la fundamentación de sus decisiones al conocer de un recurso de nulidad, más que instruir a través de autos acordados a los tribunales de su jurisdicción sobre la forma de fundamentar la sentencia. Con todo, esta última ha sido la vía escogida por la Corte Suprema, que el 10 de enero de 2001 acordó impartir a las Cortes de Apelaciones de La Serena y de Temuco, a fin de que las comunicaran a sus respectivos tribunales, un conjunto de instrucciones referidas, entre otras materias, a la forma de dictar sen- 
Son varias las razones que pueden explicar estas vacilaciones al momento de definir un modelo de fundamentación exhaustiva de la declaración de hechos probados, capaz de desarrollar satisfactoriamente las directrices fijadas por el CPP. El factor clave a mi juicio es la inexistencia en nuestra práctica jurídica de una cultura asentada de la motivación de los hechos en la que la interpretación de la nueva regulación procesal penal pueda encontrar apoyo. La libertad en la valoración de la prueba y la nueva exigencia de motivación de las conclusiones probatorias constituyen, desde esta perspectiva, novedades necesitadas de una red conceptual que las sustente y que evite la devaluación de la segunda y la disolución de la primera en arbitrariedad. Veíamos antes como en otros sistemas jurídicos el avance hacia una concepción racional de la libre valoración de la prueba y hacia un modelo exhaustivo de motivación ha sido lento y laborioso. Hoy está claro en ese contexto que para llegar a buen puerto es necesaria una teoría que precise cuáles son los criterios de racionalidad que deben orientar la deliberación y estructurar la justificación de las conclusiones probatorias. ${ }^{16}$ También la doctrina chilena debiera asumir ese desafío, si quiere evitar que la antigua cultura judicial, reacia a la justificación de la quaestio facti, termine por imponerse a los buenos propósitos del CPP. ${ }^{17}$

Pero es necesario un paso previo antes de colmar este vacío. Es preciso desanudar un equívoco conceptual que rodea a la noción de prueba (en el sentido de resultado probatorio) y que constituye el primer obstáculo para el desarrollo de una nueva cultura de la fundamentación de los hechos. Se trata de la vigencia, más o menos consciente, entre nuestros juristas y jueces, de una noción subjetivista de prueba, que la vincula al

tencias definitivas en los nuevos procesos penales (Acta $\mathrm{N}^{\circ} 79-2001$ ), que luego fueron extendidas al resto de los tribunales de la República (agradezco a Victoria Coñuecar el haberme advertido de la existencia de este acuerdo). Es interesante notar cómo esas instrucciones omiten cualquier referencia a la forma que debe asumir la justificación de las conclusiones probatorias a fin de satisfacer la exigencia de ser "reproducible". Sobre esa parte de la fundamentación ellas se limitan a disponer que "Respecto del apartado signado con la letra c) del artículo citado [342 del CPP], se hará una relación precisa y muy abreviada del o de los hechos acreditados, de sus circunstancias modificatorias y de los elementos de prueba que los fundamenten, en cumplimiento a lo dispuesto en el artículo 297 del Código Procesal Penal. En igual forma se hará referencia a continuación de la prueba producida y desestimada". Una sentencia que ofrece esperanzas de una inversión en esta tendencia a omitir la cuestión del carácter "reproducible" del razonamiento justificativo es la ya citada supra al final de la nota 13. En ella se hace expresa mención a la exigencia que "la fundamentación permita la reproducción del razonamiento utilizado para alcanzar las conclusiones a que llegare la sentencia" y se precisa que "se pretende por el legislador, en consecuencia, que quien lea el fallo esté en condiciones de rehacer el curso de las reflexiones de su autor, pudiendo reconocer la concatenación de las razones que lo han movido a convencerse de esta o aquella conclusión" (considerando sexto).

${ }^{16}$ Cfr., por ejemplo, Taruffo, M., La prueba..., cit., pp. 241ss. y 420ss.; Gascón Abellán, M., op. cit., pp. 161ss.; Ferrer Beltrán, "Derecho a la prueba...", cit., p. 29.

${ }^{17}$ Desde esta perspectiva, los trabajos hasta ahora publicados sobre la exigencia de fundamentación de los hechos en el nuevo sistema procesal penal contienen indicaciones valiosas pero insuficientes, en mi opinión, para ofrecer una orientación clara a la práctica judicial: Vid. Baytelman, A., op. cit.; Coloma, R., "La obligación de motivar los hechos en las sentencias penales", en AAVV, Seminario Reforma Procesal Penal, U. Católica de Temuco - Conosur - Lexis Nexis Chile, Santiago y, del mismo autor, "Los límites del recurso de nulidad como mecanismo de control de la decisión sobre los hechos", Revista de Derecho- Universidad Católica de Temuco, No III, 2002; Avilés, L., "Hechos y su fundamentación en la sentencia, una garantía constitucional", Revista de Estudios de la Justicia, U. de Chile, 4, 2004. 
convencimiento psicológico del juez o tribunal, de modo que, según esa concepción, decir que un hecho (o, más precisamente, un enunciado que afirma la ocurrencia de un hecho) está probado significa que el juez ha llegado a la convicción que ese hecho ha ocurrido. ${ }^{18}$ Dedicaré la última sección de este trabajo al análisis de la sugestión que esa noción subjetivista de prueba ejerce y de los peligros que envuelve para el desarrollo de una cultura de la motivación de los hechos.

\section{LA SUGESTIÓN Y LOS PELIGROS DE LA NOCIÓN SUBJETIVISTA DE PRUEBA}

\subsection{La tentación del subjetivismo: libre valoración y "convicción más allá de toda duda razonable"}

La noción subjetivista de prueba resulta consistente con la concepción de la libre valoración de la prueba que la asocia a la íntima convicción del juez y la concibe no sólo como una regla negativa, que excluye la tasación legal de las pruebas, sino además como una regla positiva que remite a la creencia del juez como criterio de decisión sobre la prueba. Aunque en las últimas décadas esa concepción de la libre valoración de la prueba ha sido desechada y sustituida por una concepción racionalista, el lastre de la noción subjetivista de prueba ha resultado más difícil de abandonar. ${ }^{19}$

Esto es lo que parece ocurrir también en Chile. Así, en el contexto del proceso penal, la incorporación del principio de la libre convicción ha estado marcada por una notable unanimidad de la doctrina procesal en torno a una concepción "racional y justificada" del mismo, según la cual éste no libera al juez de la sujeción a las "reglas de la sana crítica" o del "correcto entendimiento humano". ${ }^{20}$ Con todo, al mismo tiempo sigue vigente, de modo soterrado, en la misma doctrina y en nuestra práctica judicial, una noción subjetivista de la prueba, que entiende que el objetivo fundamental de la actividad probatoria es la de lograr la convicción del tribunal y que vincula conceptualmente la prueba de un hecho con la adquisición por parte del tribunal del estado mental consistente en la creencia en la ocurrencia de ese hecho. ${ }^{21}$

${ }^{18}$ Un excelente análisis y crítica de la noción subjetivista de prueba puede verse en Ferrer Beltrán, J., Prueba y verdad..., cit., pp. 90 ss.

${ }^{19} \mathrm{Al}$ predominio de dicha concepción entre los procesalistas españoles y, en general, los continentales se refiere Ferrer Beltrán, J., "Derecho a la prueba..", cit., p. 30.

${ }^{20}$ Cfr., por ejemplo, Tavolari, R., "Variaciones sobre la prueba en el proceso", en Revista de Derecho y Jurisprudencia, Tomo XCV, N² 2, 1998, pp. 47 y 51; Chahuán, S., Manual del nuevo procedimiento penal, Editorial Jurídica Conosur, Santiago 2001, pp. 298-301; Carocca, A., El nuevo proceso penal, Editorial Jurídica La Ley, Santiago, 2003, pp. 228-9; Horvitz, M. I. y López, J., Derecho procesal penal chileno, Tomo II, Editorial Jurídica de Chile, Santiago, 2004, pp. 149ss.

${ }^{21}$ La vigencia de la noción subjetivista de prueba en nuestra práctica jurídica es "soterrada" porque no hay, en nuestra doctrina, estudios generales dedicados al concepto de prueba que acepten de manera reflexiva esa concepción. Lo que encontramos son diversas alusiones a la convicción o persuasión del juez respecto de la ocurrencia de los hechos que son objeto del proceso como finalidad de la prueba: cfr. por ejemplo, 
Incluso el propio Código Procesal Penal parece vacilar y ceder a la sugestión del subjetivismo cuando fija el estándar de prueba para condenar recurriendo a la fórmula de la "convicción más allá de toda duda razonable" (artículo 340 del CPP). ${ }^{22}$ Así resulta al menos de la lectura dominante de esa fórmula, que la interpreta en clave subjetivista. Horvitz y López son los autores que con más detenimiento analizan la cuestión. ${ }^{23}$ Luego de dar cuenta del origen de dicha fórmula en el derecho anglosajón y de reseñar las principales interpretaciones que ella ha recibido en los Estados Unidos, los autores defienden como acertado el criterio que la identifica con la idea de "certeza moral", "utilizada como un concepto descriptivo del estado mental que implica el estándar", que "exige del juez que esté personalmente convencido de la verdad de un hecho". ${ }^{24}$ A su juicio la identificación del estándar de prueba con la idea de certeza resulta conveniente "porque este concepto sí tiene en Chile una larga tradición y reconduce a los jueces, por lo tanto, a la utilización de parámetros a los que se encuentran habituados”. ${ }^{25}$

La larga tradición a la que Horvitz y López se refieren es la que se formó a la luz del artículo 456bis del Código de Procedimiento Penal de 1906 -que establecía que "Nadie puede ser condenado por delito sino cuando el tribunal que lo juzgue haya adquirido, por los medios de prueba legal, la convicción de que realmente se ha cometido un hecho punible y que en él ha correspondido al procesado una participación culpable y penada por la ley"-, interpretado como una exigencia de "certeza legal condenatoria y certeza moral absolutoria”. ${ }^{26}$ Para notar el sesgo subjetivista de la noción de prueba en esa tradición creo que bastan estas dos muestras: la primera, una cita del Mensaje del Código de 1906 que indica que "si esta convicción [adquirida por los medios de prueba legal] no llega a formarse, el juez podrá absolver sin otro fundamento y cualesquiera que sean los antecedentes que el proceso arroje contra el reo” y, la segunda, una sentencia de

R. Tavolari, op. cit., p. 38 (donde se define la tarea de valoración de la prueba como la de determinar su "fuerza persuasiva"); Paillás, E., Estudios de Derecho Probatorio, Editorial Jurídica de Chile, Santiago, 2002, p. 14 (donde se indica como fin de la prueba "obtener la convicción del juez sobre la verdad de las afirmaciones de las partes") y, del mismo autor, La prueba en el proceso penal, Editorial Jurídica de Chile, Santiago 1982 , p. 32 (donde se hace referencia a la necesidad del "asentimiento que [el juez] dé en su fuero interno a la reconstrucción de los hechos”); Carocca, A., Manual de Derecho Procesal, Tomo II, Lexis Nexis, Santiago, 2003, pp. 144 y 151-152 (donde se define a la prueba como la actividad "destinada a formar el convencimiento del juzgador").

${ }^{22}$ La tensión es notada por R. Coloma ("Panorama general de la prueba en el juicio oral chileno", en Id., La prueba en el nuevo proceso penal, Lexis Nexis, Santiago, 2003, pp. 26ss.), quien detecta una contradicción entre el artículo 297 CPP, que establecería un criterio racional de valoración de la prueba, y el artículo 340 $\mathrm{CPP}$, que fijaría en cambio un criterio puramente subjetivo. En mi opinión la contradicción puede disolverse a través de una interpretación no subjetivista del estándar de prueba más allá de toda duda razonable (sobre la que ofreceré alguna indicación preliminar hacia el final de este trabajo). Eso no impide reconocer, por cierto, el aire fuertemente subjetivista del tenor literal del artículo 340.

${ }^{23}$ Vid. también Riego, C., Nuevo estándar de convicción, Informe de Investigación Jurídica, U. Diego Portales, $\mathrm{N}^{\circ}$ 17, Santiago, 2003.

${ }^{24}$ Horvitz, M. I. y López, J., op. cit., p. 163.

${ }^{25}$ Ibid., p. 164.

${ }^{26}$ Cfr. Morales Robles, E., Explicaciones de derecho procesal. Tomo III: Derecho Procesal Penal, impresión privada, Santiago, 1987, pp. 262-3. 
la Corte Suprema de diciembre de 1997 en la que interpreta la disposición en cuestión como "un llamado del legislador al fuero íntimo del juez y, por lo tanto, (..) un concepto imponderable para alguien que no sea el destinatario directo de él”. ${ }^{27}$

\subsection{Los peligros de la noción subjetivista de prueba: la imposibilidad de la justificación}

La noción subjetivista de prueba, que vincula los enunciados declarativos de hechos probados con la convicción o la creencia del juez en la verdad de su ocurrencia, pone a la exigencia de fundamentación en un callejón sin salida. Eso porque las creencias son algo que nos sucede, algo cuya ocurrencia no depende de nuestra voluntad, y puesto que sólo los actos voluntarios admiten justificación, no habría entonces posibilidad de justificar el resultado de la valoración de la prueba realizada por el juez. ${ }^{28}$ Como dice Ferrer "la única motivación necesaria de la decisión adoptada es que ésta se corresponda con el íntimo convencimiento del juez, que ésa es su creencia”. ${ }^{29}$ Eventualmente podría requerirse la explicación de las causas que le han llevado a esa creencia, pero, por una parte, el cotejo de la efectividad de esa creencia y sus causas es prácticamente imposible y, por otra, una explicación es conceptualmente distinta de una justificación, para la que importa no la efectividad de las causas sino la validez de las razones justificativas. ${ }^{30}$

El peligro que la noción subjetivista de prueba entraña para la exigencia de fundamentación de las conclusiones probatorias se ha manifestado ya en nuestra práctica judicial con ocasión de la controversia relativa a la extensión de la exigencia de motivación (y de su control a través del recurso de nulidad) a las sentencias absolutorias, que ha dado lugar a algunas sentencias dividas de la Corte Suprema. ${ }^{31}$ En una de ellas el ministro Milton Juica justifica su voto disidente, sosteniendo la tesis de que dicha exigencia no puede tener el mismo alcance en las sentencias condenatorias y en las absolutorias y que en estas últimas no cabe, en cualquier caso, la anulación por una insuficiente justificación. ${ }^{32}$ Los argumentos de Juica se apoyan en la asimilación del estándar de prueba más allá de toda duda razonable a la exigencia de "certeza moral” del antiguo Código de

${ }^{27}$ Fallos del Mes, No 469-4, 1997, p. 2336.

${ }^{28}$ Una cosa diferente es la justificación del contenido de la creencia (no “creo que $p$ ”, sino “p”), pero para la justificación de la proposición es irrelevante que alguien crea en ella. Cfr. Cohen, L. J., "Belief

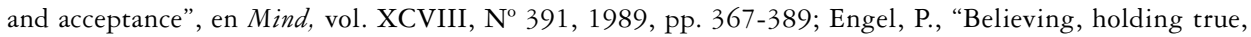
and accepting”, en Philosophical Explorations, Vol 1, No 2, 1998, pp. 140-151; Ferrer Beltrán, J., Prueba y verdad..., cit., pp. 95 ss.

${ }^{29}$ Ferrer Beltrán, J., Prueba y verdad..., cit., p. 96.

${ }^{30} \mathrm{Vid}$. Accatino, D., "Notas sobre la aplicación de la distinción entre contextos de descubrimiento y de justificación en el razonamiento judicial”, Revista de Derecho, Universidad Austral de Chile, Vol. XIII, 2002.

${ }^{31}$ Sobre esa controversia vid. Horvitz, M. I. y López, J., op. cit., pp. 423ss. y Villarroel, P., op. cit., pp. 30ss.

${ }^{32}$ Contra Pascual Pichún Paillalao y otros, R.U.C. No 0100083503-6, R.I.T. No 2-2003, recurso de nulidad ante la Corte Suprema Rol No 1743-03; la misma tesis es sostenida por Horvitz, M. I. y López, J., op. cit., pp. 424-6. 
1906 (considerando $7^{\circ}$ ) y en la idea según la cual los vacíos en la fundamentación “...no tienen para el caso de la sentencia absolutoria la capacidad de influir sustancialmente en la decisión de absolver que adquirió el tribunal, porque ha quedado en evidencia que la prueba presentada por los acusadores provocó en los sentenciadores el estado de duda razonable que impide, por supuesto, adquirir la conciencia moral e intima de condena" (considerando $13^{\circ}$; las cursivas han sido añadidas).

Podría argüirse tal vez que en realidad la tesis de Juica no significa un "peligro" para la exigencia de fundamentación, ya que ésta sólo tendría sentido como aspecto del derecho de defensa del acusado y la tesis en cuestión mantiene con respecto a la sentencia de condena un patrón exigente de justificación. Sin embargo, este argumento está expuesto al menos a dos objeciones. Por una parte, la función de la exigencia de fundamentación como garantía del imputado es ciertamente central, pero no es la única función que cabe atribuirle; ella tiene también una dimensión pública como freno a la arbitrariedad judicial y mecanismo para el control procesal y extra-procesal de la sujeción de los jueces a la ley (sujeción que supone, en primer lugar, que los jueces comprueben adecuadamente si se han producido o no los hechos condicionantes de las normas jurídicas aplicables). Por otra parte, nada asegura que la noción subjetivista de prueba y la atenuación de la exigencia de motivación no se extiendan también a la sentencia condenatoria a través de argumentos comos los aducidos en España por De la Oliva, quien sostiene que "no es exigible, ni legal ni racionalmente, que toda sentencia dé cuenta detallada del porqué de cada declaración de certeza positiva de un hecho" pues no parece razonable "pedir que se exprese lo que pertenece a los internos procesos psicológicos de convicción, muchas veces parcialmente objetivables, sí, pero también parcialmente pertenecientes al ámbito de lo inefable". ${ }^{33}$ Recordemos, de hecho, que actualmente parece predominar, también respecto de las sentencias condenatorias, un patrón de fundamentación que sustituye la valoración individual de los diversos medios de prueba aportados y la articulación de las cadenas de inferencias que justifican la conclusión probatoria por una muchas veces apodíctica valoración global y que hasta ahora no ha sido objeto de revisión crítica a través de la anulación de las sentencias. La razón de este riesgo es clara: no es posible sostener al mismo una noción subjetivista de prueba para la absolución y otra racionalista para la condena, un mínimo de consistencia exige una única noción general de prueba.

\subsection{Otros defectos de la noción subjetivista de prueba}

Además de ser inconsistente con la vigencia de una exigencia de justificación de las conclusiones probatorias, la noción subjetivista adolece de otras dificultades que la revelan como una inadecuada reconstrucción conceptual, incapaz de dar cuenta de nuestras prácticas procesales.

${ }^{33}$ De la Oliva, A., "De la sentencia”, en De la Oliva et al., Derecho Procesal Penal, Centro de Estudios Ramón Areces, Madrid, 2002 (5 ${ }^{\mathrm{a}}$ ed.), p. 514. 
En primer lugar ella no puede dar cuenta de la falibilidad judicial, pues según esa noción de prueba la convicción o creencia es condición suficiente para que una proposición esté probada y carece de sentido hablar de error respecto de la ocurrencia de ese estado mental. En otros términos, la noción subjetivista de prueba hace equivalentes dos situaciones que parece razonable poder distinguir conceptualmente: que un enunciado acerca de la ocurrencia de un hecho haya sido "tenido por probado" por algún sujeto y que ese enunciado "esté probado". ${ }^{34}$ Sólo si ambas situaciones pueden distinguirse adquiere sentido la existencia de controles relativos a las decisiones judiciales sobre los hechos (como los que prevé nuestro sistema procesal penal a través del motivo absoluto de nulidad por defectos en la fundamentación de la declaración de hechos probados).

En segundo lugar, la noción subjetivista de prueba no permite dar cuenta de los numerosos casos en que los jueces deciden -y, en varios de ellos, deben decidir- contra sus creencias, como ocurre, por ejemplo, si el juez dispone de elementos de juicio, sobre los que basa su creencia, que no han sido incorporados al proceso y que, por lo tanto, no puede tomar en cuenta en su decisión. Esta característica de nuestra práctica procesal está conectada con un rasgo general de la prueba, que es su relatividad respecto de los elementos de juicio aportados al proceso (que se conecta con la obligación del juez de decidir iuxta alligata atque probata, ateniéndose solo a las pruebas válidamente aportadas al proceso $)^{35}$. La noción de prueba que remite a la creencia del juzgador no permite dar cuenta de esta peculiaridad de la prueba judicial pues la creencia es un estado mental independiente del contexto. ${ }^{36}$ Si bien nuestras creencias pueden cambiar a lo largo del tiempo, en un mismo momento no podemos creer en algo con relación a un contexto y no creerlo con relación a otro contexto. Ferrer Beltrán lo ilustra muy bien: "No podemos, por ejemplo, creer o no creer que Hong Kong es una ciudad ruidosa en función de (...) si lo pregunta el alcalde de la ciudad o un ecologista (aunque es perfectamente posible responder de forma distinta a uno y a otro, en alguno de los dos casos se estará mintiendo respecto de la creencia que se tiene). Y un juez no puede, por ejemplo, creer que Juan mató a Pedro cuando ejerce su función de juez y no creerlo cuando no la ejerce (en tanto que simple ciudadano)". 37

\section{Perspectivas}

Las dificultades antes expuestas sugieren que es necesario abandonar la noción subjetivista de prueba y sustituirla por una noción que haga posible hablar de la justificación de la decisión judicial sobre la prueba y que permita dar cuenta de su falibilidad y de su carácter relacional respecto de los elementos de juicio aportados al proceso. Sólo una

\footnotetext{
${ }^{34}$ Vid. Ferrer Beltrán, J., Prueba y verdad..., cit., pp. 36-7 y 109.

${ }^{35}$ Cfr. Mendonca, D., op. cit., pp. 77-8 y Ferrer Beltrán, J., Prueba y verdad..., cit., pp. 93-4 y 98-9.

${ }^{36}$ Cfr. Engel P., op. cit., pp. 143-4.

${ }^{37}$ Ferrer Beltrán, Prueba y verdad..., cit., p. 98.
} 
vez clarificada esta cuestión conceptual previa se podrán abordar satisfactoriamente las dificultades que ha suscitado en nuestra práctica jurídica la interpretación del contenido y el alcance de la exigencia de fundamentación de las conclusiones probatorias.

Aunque afrontar esa cuestión excede a los propósitos de este estudio y será objeto de futuros trabajos, las consideraciones críticas antes expuestas permiten vislumbrar, al menos, el camino para articular una noción adecuada de prueba, pues de ellas se sigue que afirmar que una proposición está probada tiene que ser equivalente a afirmar algo en relación con los elementos de juicio aportados al proceso y, además, algo que -desde el punto de vista conceptual- sea susceptible de justificación y de evaluación crítica. Una reconstrucción que parece cumplir esas condiciones es la que ha sido explorada en recientes trabajos de Ferrer Beltrán y según la cual decir que una proposición está probada equivale a decir que hay elementos de juicio suficientes para aceptar o dar por verdadera a esa proposición. ${ }^{38} \mathrm{La}$ aceptación es, a diferencia de la creencia, un acto voluntario que admite justificación -la que deberá referir a la suficiencia de los elementos de juicio- y la suficiencia de los elementos de juicio es, a diferencia de la afirmación de una creencia, una circunstancia respecto de la cual cabe, desde el punto de vista conceptual, la equivocación y la crítica.

Es interesante notar como esta noción de prueba permitiría abordar las preguntas sobre el estándar de prueba más allá de toda duda razonable y sobre la "reproducibilidad" del razonamiento probatorio de un modo que las libere de las cargas del subjetivismo, esto es, como preguntas sobre las condiciones y las formas de justificación de la suficiencia de los elementos de juicio disponibles. Examinar con detenimiento esa noción de prueba y reformular y responder esas preguntas constituirá, como he dicho, el objeto de próximas investigaciones.

\section{BIBLIOGRAFÍA}

Accatino, D., "Notas sobre la aplicación de la distinción entre contextos de descubrimiento y de justificación al razonamiento judicial”, Revista de Derecho, Universidad Austral de Chile, Volumen XIII, 2002, pp. 9-25.

- "La fundamentación de las sentencias: ¿un rasgo distintivo de la judicatura moderna?", Revista de Derecho, Universidad Austral de Chile, Volumen XV, 2003, pp. 9-35.

Andrés Ibañez, P., "Acerca de la motivación de los hechos en la sentencia penal", Doxa, 12, 1992, pp. 257-299.

- “'Carpintería' de la sentencia penal (en materia de 'hechos')”, Revista del Poder Judicial, 49, 1998 , pp. 393-428.

- "La argumentación probatoria y su expresión en la sentencia", en Estudios de Derecho judicial, 32, 2000.

Amodio, E., "Motivazione della sentenza penale”, Enciclopedia del diritto, vol. XXVII, Giuffrè, Milán, 1977.

${ }^{38}$ Cfr. Ferrer Beltrán, J., Prueba y verdad..., .cit., especialmente pp. 37ss. y 101 ss. 
Avilés, L., "Hechos y su fundamentación en la sentencia, una garantía constitucional”, Revista de Estudios de la Justicia, U. de Chile, 4, 2004.

Baytelman, A., "La fundamentación de la sentencia en el nuevo proceso penal", en AAVV, Nuevo Proceso Penal, Conosur, Santiago, 2000.

BeCCaria, C., De los delitos y las penas, trad. cast. de J. A. de las Casas, FCE, México, 2000 (incluye facsímil de la primera edición italiana), 1764.

Bello, A., "Necesidad de fundar las sentencias", en El Araucano, $\mathrm{N}^{\circ}$ 197, 20 de junio, ahora en Id., Escritos jurídicos, políticos y universitarios, selección y prólogo de Agustín Squella, Edeval, Valparaíso, 1979, 1834, pp. 107-115.

Bentham, J., Tratado de las pruebas judiciales, trad. cast. M. Ossorio, Ediciones Jurídicas EuropaAmérica, Buenos Aires, 1959, 1823.

Boffill, J., "La prueba en el proceso penal", en Revista de Derecho y Jurisprudencia, tomo XCI, $\mathrm{N}^{\circ} 1,1994$.

Carocca, A., El nuevo sistema procesal penal, Editorial Jurídica La Ley, Santiago, 2003.

- Manual de Derecho Procesal, Tomo II, Lexis Nexis, Santiago, 2003.

- Centro de Documentación Defensoría Penal Pública, Análisis de los controles de detención y absoluciones producido en la IV Región de Coquimbo 2001-2002, Santiago, 2004.

Cohen, M. Y Nagel, E., Introducción a la lógica y al método científico, Tomo II, Amorrotu Editores, Buenos Aires, 2000, 1934.

CoHen, L. J., The probable and the provable, Oxford U. Press, Oxford, I 977.

- Introduzione alla filosofia dell'induzione e della probabilità, Giuffrè, Milán, 1998, 1989.

- "Belief and acceptance", en Mind, vol. XCVIII, No 391, 1989, pp. 367-389.

Coloma, R., "La obligación de motivar los hechos en las sentencias penales", en AAVV, Seminario Reforma Procesal Penal, U. Católica de Temuco, Conosur-Lexis Nexis Chile, Santiago, 2001, pp. 225-241.

- "Los límites del recurso de nulidad como mecanismo de control de la decisión sobre los hechos", Revista de Derecho de la Universidad Católica de Temuco, No III, 2002, pp. 55-77.

- "Panorama general de la prueba en el juicio oral chileno", en $I d$. (ed.), La prueba en el nuevo proceso penal, Lexis Nexis, Santiago, 2003.

Comanducci, P., "La motivazione in fatto", en G. Ubertis (ed.), La conoscenza del fatto nel processo penale, Giuffrè, Milán, 1992 pp. 215-244.

Couture, E., Los fundamentos del Derecho procesal civil, Editorial Aniceto López, Buenos Aires, 1942.

ChauÁn, S., Manual del nuevo procedimiento penal, Editorial Jurídica Conosur, Santiago, 2001.

De la Oliva, A., "De la sentencia", en De la Oliva et al., Derecho Procesal Penal, 5 a edición, Centro de Estudios Ramón Areces, Madrid, 2002.

ENGel, P., "Believing, holding true, and accepting", en Philosophical Explorations, Vol. 1, № 2, 1998, pp. 140-151.

Fernández López, M., Prueba y presunción de inocencia, Iustel, Madrid, 2005.

Ferrajoli, L., Derecho y razón. Teoría del garantismo penal, trad. cast. de P. Andrés, A. Ruiz, J.C. Bayón, J. Terradillos, Trotta, Madrid, 1995, 1989.

Ferrer, J., La prueba en el derecho, Marcial Pons, Madrid, 2002.

- "Derecho a la prueba y racionalidad de las decisiones judiciales", Jueces para la democracia, 47, 2003, pp. 27-34.

Gascón Abellán, M. (1999): Los hechos en el derecho. Bases argumentales de la prueba, Marcial Pons, Madrid.

GonZÁlez LAgIER, D. (2003a): "Hechos y argumentos (Racionalidad epistemológica y prueba de los hechos en el proceso penal) (I)", Jueces para la democracia, 46, pp. 17-26. 
- $\quad$ "Hechos y argumentos (Racionalidad epistemológica y prueba de los hechos en el proceso penal) (II)", Jueces para la democracia, 47, 2003b, pp. 35-51.

Hanisch, H., "Contribución al estudio del principio y de la práctica de fundamentación de las sentencias en Chile durante el siglo XIX”, en Revista de Estudios histórico-jurídicos, VII, 1982, pp. 131-173.

Hempel, C. y Oppenheim, P., "La lógica de la explicación”, en Hempel, C. (ed.), La explicación científica. Estudios de filosofía de la ciencia, Piados, Buenos Aires, 1979, 1948.

Horvitz, M. I. y López J., Derecho procesal penal chileno, Tomo II, Editorial Jurídica de Chile, Santiago, 2004.

IACoviello, F.M., La motivazione della sentenza penale e il suo controllo in cassazione, Giuffrè, Milán, 1997.

Igartua Salaverría, J., Valoración de la prueba, motivación y control en el proceso penal, Tirant lo Blanch, Valencia, 1995.

- La motivación de las sentencias, imperativo constitucional, Centro de Estudios Políticos y Constitucionales, Madrid, 2003.

Lo, H. L., "The judicial duty to give reasons", Legal Studies, vol. 20, No 1, 2000, pp. 42-65.

Mendonca, D, Interpretación y aplicación del derecho, Servicio de Publicaciones de la Universidad de Almería, Almería, 1997.

Morales Robles, E., Explicaciones de derecho procesal. Tomo III: Derecho Procesal Penal, impresión privada, Santiago, 1987.

Paillás, E., La prueba en el proceso penal, Editorial Jurídica de Chile, Santiago, 1982.

- Estudios de Derecho Probatorio, Editorial Jurídica de Chile, Santiago, 2002.

Prambs, C., El control del establecimiento de los hechos en las sentencias penales, Editorial Metropolitana, Santiago, 2005.

Riego, C., Nuevo estándar de convicción, Informe de Investigaciones Jurídicas, U. Diego Portales, Santiago, 2003.

Romero, A., "Las consideraciones de hecho y de derecho en la sentencia: un derecho esencial del justiciable", Revista Chilena de Derecho, Vol. 27 No 3, 2000, pp. 571-579.

Senese, S., "La motivazione della veritá fattuale", en L. Gianformaggio (ed.), Le ragioni del garantismo. Discutendo con Luigi Ferrajoli, Giappichelli, Turín, 1993 , pp. 322-339.

Taruffo, M. (1975): La motivazione della sentenza civile, Cedam, Padova.

- "La fisionomia della sentenza in Italia”, en VVAA, La sentenza in Europa. Metodo, tecnica e stile (Atti del convegno internazionale svolto a Ferrara 10-12 ottobre 1985), Cedam, Padua, 1988, pp. 180-214.

- "Motivazione della sentenza (diritto comparato e straniero)", Enciclopedia Giuridica, Treccani, Roma, 1990.

- La prova dei fatti giuridici, Giuffré, Milán, 1992.

- "La valutazione delle prove. Prova libera e prova legale. Prove e argomenti di prova", en Documenti Giustizia, No 6, 1995.

TAvolari, R., "Variaciones sobre la prueba en el proceso", en Revista de Derecho y Jurisprudencia, Tomo XCV, No 2, pp. 37-59, 1998.

Twining, W., Rethinking Evidence. Exploratory Essays, Nortwestern U. Press, Evanston, 1994, 1990.

Ubertis, G., La prova penale. Profili giuridici ed epistemologici, UTET, Turín, 1995.

Villanueva, I., La fundamentación de los hechos en las sentencias penales. Una comparación entre el antiguo y el nuevo proceso penal, Tesis para optar al Grado de Licenciado en Ciencias Jurídicas y Sociales realizada bajo la dirección de Daniela Accatino, Universidad Austral de Chile, inédita, 2005. 
Villarroel, P., La justificación de la "duda razonable" en las nuevas sentencias penales, Tesis para optar al Grado de Licenciado en Ciencias Jurídicas y Sociales realizada bajo la dirección de Daniela Accatino, Universidad Austral de Chile, inédita, 2005.

Walter, G., Libre apreciación de la prueba, Temis, Bogotá, 1985, 1979.

Wroblewski, J., Sentido y hecho en el derecho, Servicio Editorial del País Vasco, San Sebastián, 1989. 